\title{
Low Shear Stress Upregulates CX3CR1 Expression by Inducing VCAM-1 via the NF-KB Pathway in Vascular Endothelial Cells
}

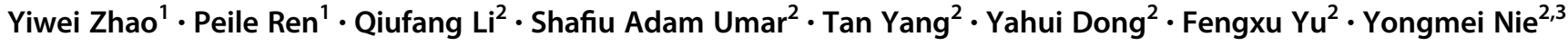

Received: 7 July 2019 / Accepted: 6 July 2020 / Published online: 19 July 2020

(C) The Author(s) 2020

\begin{abstract}
Atherosclerosis is a significant cause of mortality and morbidity. Studies suggest that the chemokine receptor CX3CR1 plays a critical role in atherogenesis. Shear stress is an important mechanical force that affects blood vessel function. In this study, we investigated the effect of shear stress on CX3CR1 expression in vascular endothelial cells (VECs). First, cells were exposed to different shear stress and then CX3CR1 mRNA and protein were measured by quantitative RT-PCR and western blot analysis, respectively. CX3CR1 gene silencing was used to analyze the molecular mechanisms underlying shear stressmediated effects on CX3CR1 expression. CX3CR1 mRNA and protein expression were significantly increased with 4.14 dyne $/ \mathrm{cm}^{2}$ of shear stress compared with other tested levels of shear stress. We observed a significant increase in CX3CR1 mRNA levels at $2 \mathrm{~h}$ and CX3CR1 protein expression at $4 \mathrm{~h}$. CX3CR1-induced VCAM-1 expression in response to low shear stress by activating NF-KB signaling pathway in VECs. Our findings demonstrate that low shear stress increases CX3CR1 expression, which increases VCAM-1 expression due to elevated NF-kB activation. The current study provides evidence of the correlation between shear stress and atherosclerosis mediated by CX3CR1.
\end{abstract}

Keywords Human vascular endothelial cells $\cdot \mathrm{CX} 3 \mathrm{CR} 1 \cdot$ Low shear stress $\cdot \mathrm{NF}-\mathrm{kB} \cdot$ Atherosclerosis

\section{Introduction}

Atherosclerosis, a disease that causes arteriostenosis due to plaque formation, is a leading cause of morbidity and mortality. Although risk factors, such as hypertension and diabetes, lead to vascular endothelial cell (VEC) dysfunction throughout the vasculature [1, 2], atherosclerosis

These authors contributed equally: Yiwei Zhao, Peile Ren

Fengxu Yu

yuluchuan@163.com

$\triangle$ Yongmei Nie

nieyongmei@126.com

1 Department of Physiology, School of Medicine, Xinjiang Medical University, Urumqi 830011 Xinjiang, PR China

2 Department of Cardiovascular Surgery, Affiliated Hospital of Southwest Medical University, Luzhou 646000 Sichuan, PR China

3 Key Laboratory of Cardiovascular and Metabolic Diseases, Affiliated Hospital of Southwest Medical University, Luzhou 646000 Sichuan, PR China preferentially occurs in arterial regions exposed to low, disturbed, or oscillating blood flow [3]. As a result of the frictional force generated by blood flow, VECs covering the vessel inner surface are constantly subjected to shear stress. Local shear stress alters VEC intracellular signaling, which leads to alterations in gene expression, cell morphology, and structural remodeling [4, 5]. In a healthy human aorta, the average wall shear stress ranges from 10 to $20 \mathrm{dyne} / \mathrm{cm}^{2}$ [6]. Normal high arterial shear stress stimulates anti-inflammatory, antiproliferative, and antithrombotic gene expression [7], but low shear stress $\left( \pm 4 \mathrm{dyne} / \mathrm{cm}^{2}\right)$ stimulates VECs to release factors that promote cell proliferation, cell adhesion, VEC dysfunction [4, 8], and atherosclerosis [9].

Inflammation plays a primary role in atherogenesis, and numerous studies have shown that the inflammatory response is a key factor in the progression of atherosclerosis in vascular disease [5]. CX3CL1 (Fractalkine, FKN), a CX3C chemokine expressed in endothelial cells, promotes firm cell adhesion and chemotaxis of leukocytes expressing CX3CR1 [10, 11]. While CX3CL1 and CX3CR1 are expressed at low levels in healthy vessels, their expression increases significantly under pathological conditions $[12,13]$, and pharmacological inhibition of CX3CR1 (the 
CX3CR1 antagonist F1) has been reported to reduce atherosclerosis [14]. DNA vaccination against CX3CR1 (DEC205-CX3CR1) decreased macrophage recruitment and significant protection from atherosclerosis [15]. In atherosclerotic vessels, the receptor CX3CR1 is expressed on monocytes. Mice deficient in CX3CR1 have previously been employed to investigate the function of monocyte survival and recruitment during atherogenesis [10, 16]. However, we also found CX3CR1 expressed in ECs. Some studies have found the association between CX3CL1-CX3CR1 and atherosclerosis [17]. The CX3CL1-CX3CR1 interaction has been shown to transmit essential survival signals in monocytes and macrophages. The absence of CX3CR1 has been shown to lead to increased death rates, inhibiting atherosclerotic lesion formation [12]. In addition, CX3CR1 plays a role in the formation of atherosclerosis.

$\mathrm{NF}-\kappa \mathrm{B}$ is a critical regulator of many cell processes, including cytokine production that influences inflammation and stress responses [18]. VCAM-1 is an important adhesion molecule involved in inflammation [19] and its expression on the vascular endothelium can be increased by pro-inflammatory cytokines [20]. Therefore, we investigated the effects of fluid shear stress on CX3CR1 expression in VECs. HUVECs were exposed to different shear stress levels for varying durations to determine mechanisms of low shear stress-induced CX3CR1 upregulation. The results indicate that low shear stress upregulates CX3CR1 expression, which subsequently induces VCAM-1 expression downstream of $\mathrm{NF}-\mathrm{\kappa B}$ activation in VECs.

\section{Material and Methods}

\section{Cell Culture}

HUVECs derived from EA.hy926 cell lines were purchased from the Shanghai Cell Bank (Shanghai, China) and maintained in HyClone ${ }^{\mathrm{TM}}$ Medium 199 (Thermo Fisher Scientific, USA) supplemented with $10 \%$ fetal calf serum and $1 \%$ penicillin and streptomycin. Cell cultures were grown in a humidified $5 \% \quad \mathrm{CO}_{2}$ air incubator at $37^{\circ} \mathrm{C}$. Pancreatin $(1 \mathrm{~mL})$ was added per culture dish to detach the cells from the plates. Cell suspensions were seeded onto sterile glass slides $(75 \times 20 \mathrm{~mm})$ coated with $1 \mathrm{~mL}$ fibronectin (BD, USA), and were further incubated in empty culture dishes.

\section{Exposure of EA.hy926 Cells to Shear Stress}

A parallel-plate flow chamber system $(185 \times 95 \times 0.8 \mathrm{~mm})$ was incorporated into a closed-loop perfusion system containing serum-free M199 medium driven by a roller pump. Shear stress was calculated according to the equation $\tau=\frac{6 \mu Q}{H^{2} W}$, here $\tau$ is shear stress, $\mu$ is medium viscosity
$(0.72 \mathrm{mPa} \cdot \mathrm{s}), \mathrm{Q}$ is volumetric flow rate, $\mathrm{h}$ is chamber height $(0.8 \mathrm{~mm})$, and $\mathrm{W}$ is chamber width $(95 \mathrm{~mm})$. Shear stress of varying levels $(0,2.37,4.14,7.11,9.47,14.21$, and $17.76 \mathrm{dyne} / \mathrm{cm}^{2}$ ) was applied to EA.hy926 cells grown on glass slides for $2 \mathrm{~h}$. The cells were then subjected to a fixed shear stress $\left(4.14\right.$ dyne $\left./ \mathrm{cm}^{2}\right)$ for different durations $(0,0.5$, $1,2,4,6,8$, and $10 \mathrm{~h}$ ).

\section{RNA Isolation and qRT-PCR}

Cellular RNA was extracted from each individual glass slide using TRIzol Reagent (\#15596-026, Life Technology, USA) according to the manufacturer's protocol. RNA quantity and quality were determined by the A260/A280 ratio using a Nano Drop 1000 spectrophotometer. Two-step reverse transcription (RT) was performed using a RevertAid First Strand cDNA Synthesis Kit (\#K1622, Thermo Fisher Scientific, USA) following the manufacturer's instructions. qRT-PCR was performed using a QuantiFast SYBR Green PCR Kit (cat. no. 204056, QIAGEN, USA). The following primers were used (Shanghai Biological Engineering Company, China): CX3CR1: forward 5'-catcaccgtcatcagcattga-3', reverse 5'-ggtagtcaccaaggcattcatt -3'; $\beta$-actin: forward 5'-ggtagtcaccaaggcattcatt-3', reverse 5'-ctccttaatgtcacgcacgat-3'. The reaction mix consisted of $2 \times$ QuantiFast SYBR Green PCR Master Mix $(10 \mu \mathrm{L})$, forward primer $(1 \mu \mathrm{L})$, reverse primer $(1 \mu \mathrm{L})$, RNase-free water $(6 \mu \mathrm{L})$, template cDNA $(2 \mu \mathrm{L})$, and RNase-free water for a total volume of $20 \mu \mathrm{L}$. The CFX96 Real-Time System (BIO-RAD, No. 785BR04347) was employed for this reaction. Relative gene expression was calculated using the $2^{-\Delta \Delta \mathrm{CT}}$ method.

\section{Western Blot Analysis}

Total cellular protein on the glass slides was extracted using RIPA lysis buffer containing protease and phosphorylase inhibitors (Thermo Fisher Scientific, USA). Protein concentration was measured using the Pierce BCA Protein Assay Kit according to the manufacturer's instructions. Proteins were separated using 12\% SDS-PAGE and transferred to polyvinylidene fluoride membranes (LOT 18071300 , Roche) by electroblotting. Membranes were incubated in 5\% skimmed milk in Tris buffered saline with Tween 20 (TBST) (Boshide, Wuhan, China) for $1 \mathrm{~h}$ to block nonspecific binding. Subsequently, the membranes were incubated overnight with either rabbit anti-CX3CR1 (1:1,000; ab8021, Abcam), NF-кB P65 (1:1,000), VCAM$1(1: 2,000)$, or rabbit anti-GAPDH $(1: 1,000$; Goodhere, China) primary antibodies at $4{ }^{\circ} \mathrm{C}$. The membranes were washed three times with TBST and incubated with secondary antibody conjugated to HRP (1:500; ZSGB-BIO, China) for $2 \mathrm{~h}$. Protein bands were visualized using a color 
Fig. 1 CX3CR1 expression in vascular endothelial cells under different levels of shear stress. a mRNA expression of CX3CR1 in vascular endothelial cells subjected to different levels of shear stress. b CX3CR1 protein expression detected by western blot analysis in vascular endothelial cells subjected to different levels of shear stress $(* P<0.05$ vs. control, $n=3$ in each group)
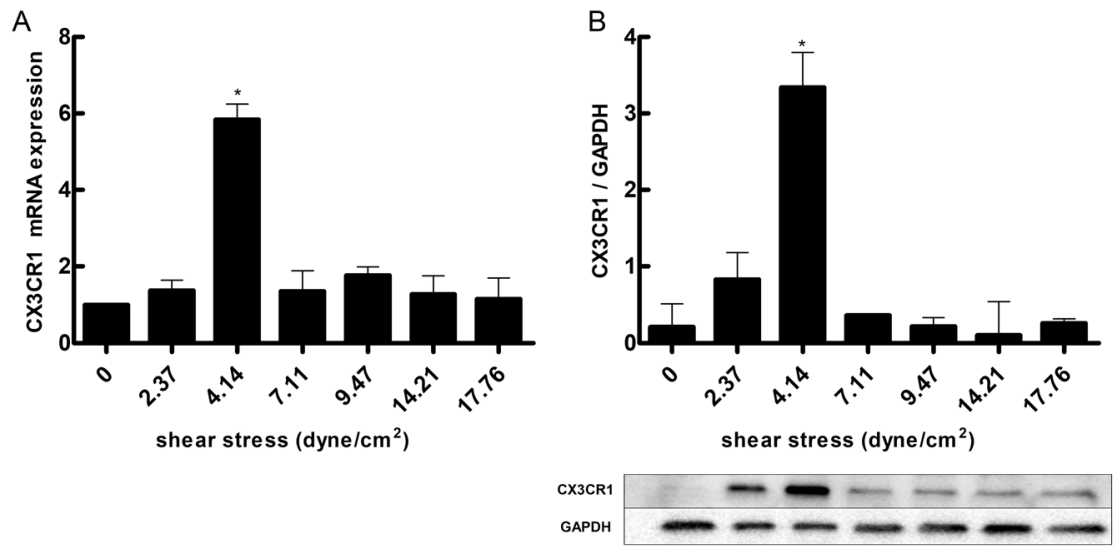

development solution (1:1) for $3 \mathrm{~min}$. Images were acquired using a chemiluminescence imager (Bio-Rad).

\section{Cell Immunofluorescence Labeling}

All incubations were performed at standard laboratory room temperature $\left(22 \pm 1{ }^{\circ} \mathrm{C}\right)$ unless otherwise stated. For cell immunofluorescence, the ECs were fixed on glass slides with $4 \%$ paraformaldehyde for $1 \mathrm{~h}$ and then washed three times using PBS. The cells were blocked with 5\% BSA-PBS (Boshide, Wuhan, China) for $30 \mathrm{~min}$, followed by overnight incubation with an appropriate primary rabbit anti-CX3CR1 antibody (1:200 dilution, catalogue no. ab8021, Abcam) at $4{ }^{\circ} \mathrm{C}$. The slides were then washed and incubated for $2 \mathrm{~h}$ with secondary biotinylated Alexa Fluor 594 anti-rabbit IgG antibody (1:200 dilution, \#8889, Cell Signaling). Studies using these antibodies have been previously published, and related details are available from the manufacturers' websites.

\section{Cell Culture and Lentiviral Infection}

The culture medium was supplemented with $10 \%$ fetal bovine serum (FBS) and 100 units $/ \mathrm{mL}$ of penicillin and streptomycin. Construct lentiviral vectors and lentivirus were produced by GENECHEM (Shanghai, China). The lentiviruses were constructed encoding sequences targeting CX3CR1 mRNA (siCX3CR1 target-CTTGTCTG ATCTGCTGTTT); empty vector was used as the negative control. Stable cell lines were generated by lentivirus infection, which was carried out in a six-well plate with serum-free M199 medium. HUVECs were transduced with lenti-si-CX3CR1 at an infection multiplicity of infection $=10$ at $37{ }^{\circ} \mathrm{C}$ with $5 \mu \mathrm{g} / \mathrm{mL}$ polybrene and enhanced for $72 \mathrm{~h}$ according to the manufacturer's guidelines. The culture medium was replaced with fresh medium containing $10 \%$ FBS, and the cells were continuously cultured for 6-8 days followed by selection with flow cytometry.

\section{Effect of the NF-KB Inhibitor PDTC on Cell Viability}

HUVECs $\left(5.0 \times 10^{3} /\right.$ well $)$ were plated and treated in 96 well plates with various concentrations of PDTC $(0,2.5,5$, 10,20 , and $40 \mu \mathrm{mol} / \mathrm{L}$ ) for $0,12,24,48$, and $72 \mathrm{~h}$. Then, $200 \mu \mathrm{L}$ of MTT (ZSGB-BIO, China) was added to the cells for $4 \mathrm{~h}$, the MTT fluid was removed, and $150 \mu \mathrm{L}$ of DMSO (Sigma, USA) was added to the wells. After shaking at a low speed for $10 \mathrm{~min}$, the optical density values of the cells were measured according to the manufacturer's instructions.

\section{Statistical Analysis}

All results are expressed as mean \pm standard error of the mean. Statistical comparisons between two groups were performed using a Student's $t$ test. Statistical comparisons of more than two groups were analyzed using one-way analysis of variance (ANOVA), the least-significant difference test, or multiple ANOVA with SPSS software version 17.0. $P$ values $<0.05$ were considered significant.

\section{Results}

\section{Fluid Shear Stress Increases CX3CR1 Expression in VECs}

To determine the effect of shear stress on CX3CR1 expression, were exposed to a range of shear stress levels (0-17.76 dyne $/ \mathrm{cm}^{2}$ ) for $2 \mathrm{~h}$. We found CX3CR1 expressed in HUVECs. After each experiment, the cells were collected to measure CX3CR1 mRNA levels and protein expression. Both CX3CR1 mRNA levels (Fig. 1a) and protein expression (Fig. 1b) were higher with $4.14 \mathrm{dyne} / \mathrm{cm}^{2}$ of shear stress compared with the other shear stress intensities. Then, evaluated the effect of shear stress duration on CX3CR1 expression, cells were exposed to $4.14 \mathrm{dyne} / \mathrm{cm}^{2}$ for various durations $(0,1,2,4,6,8$, and $10 \mathrm{~h})$. CX3CR1 mRNA levels 
Fig. 2 CX3CR1 expression in vascular endothelial cells exposed to different durations of shear stress. a CX3CR1 mRNA expression in vascular endothelial cells subjected to different shear stress durations. b CX3CR1 expression under different shear stress durations $(* P<0.05$ vs. control, $n=3$ in each group)
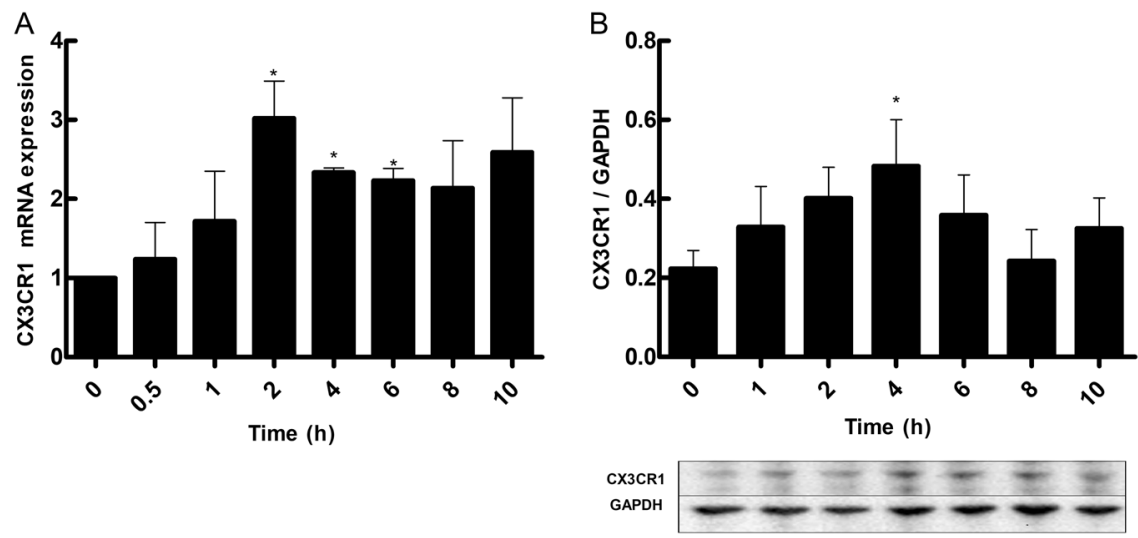

Fig. 3 CX3CR1 protein expression remained in the cell membrane after exposure to shear stress. Fluorescence images of CX3CR1 in vascular endothelial cells. The control group (a) was maintained under static conditions, and the test group (b) was subjected to low shear stress (LSS) at 4.14 dyne/ $\mathrm{cm}^{2}$ for $4 \mathrm{~h}$
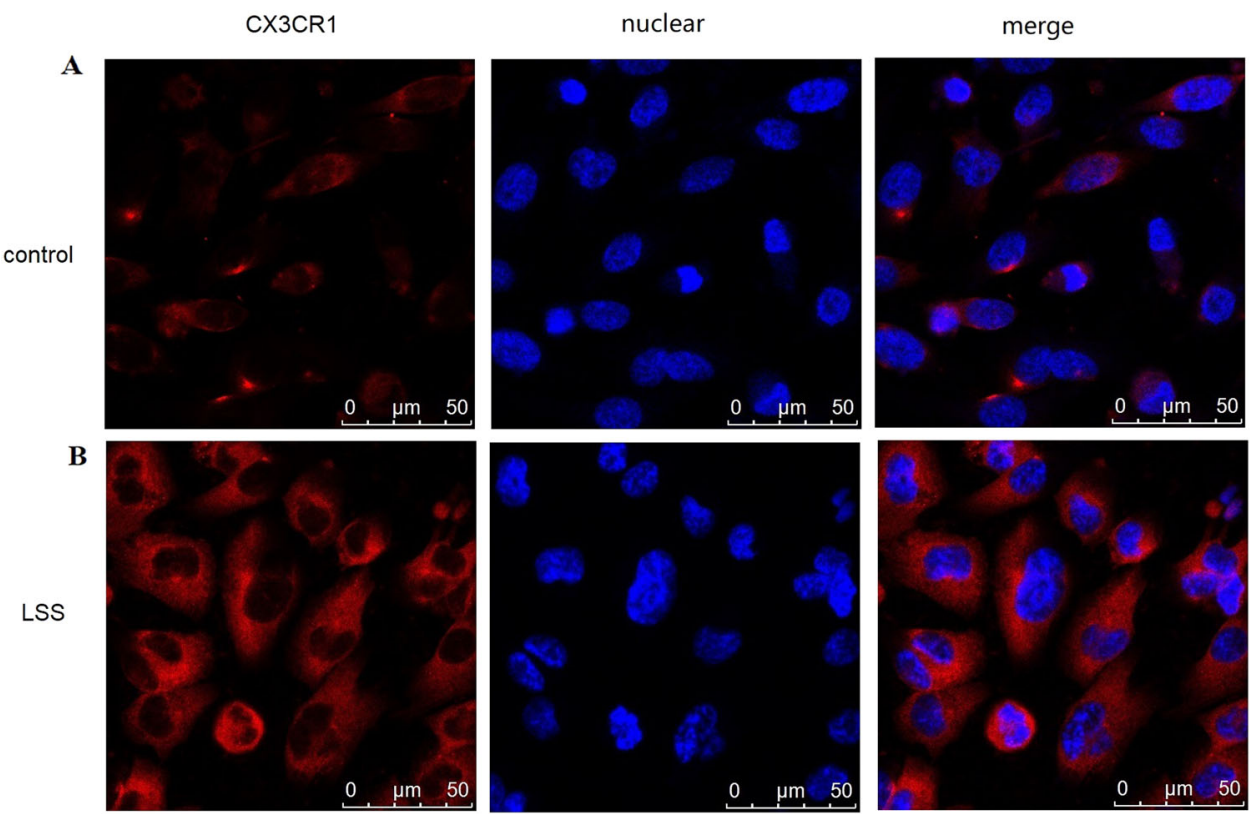

in the cells peaked at $2 \mathrm{~h}$ (Fig. 2a), and CX3CR1 protein expression in the perfusate peaked at $4 \mathrm{~h}$ (Fig. 2b). CX3CR1 protein expression remained in the cell membrane after exposure to shear stress (Fig. 3). These results indicate that CX3CR1 expression is particularly sensitive to low shear stress at 4.14 dyne $/ \mathrm{cm}^{2}$.

\section{CX3CR1 Induces VCAM-1 Expression under Low Shear Stress}

Studies have indicated that VCAM-1 expression is modified by low shear stress. However, whether VCAM-1 expression is influenced by CX3CR1 under low shear stress has not been reported. Therefore, we determined if VCAM-1 expression was altered in VECs following low shear stress-mediated upregulation of CX3CR1. Western blot analysis showed that VCAM-1 protein expression decreased after transfection with
CX3CR1 siRNA, but that VCAM-1 expression increased under low shear stress (Fig. 4a-c). These results indicate that CX3CR1 participates in the vascular inflammatory response induced by low shear stress in VECs.

\section{NF-KB Mediates CX3CR1-Induced VCAM-1 Expression under Low Shear Stress}

NF- $\mathrm{KB}$ and its regulatory genes are both directly and indirectly involved in the development of atherosclerosis. Ryan et al. demonstrated that low shear stress can promote nuclear expression of NF- $\mathrm{KB}$ [21]. Therefore, we investigated if the NF- $\mathrm{KB}$ signaling pathway is involved in low shear stress-mediated upregulation of CX3CR 1 . We found that downregulation of CX3CR1 by CX3CR1 siRNA decreased expression of the NF- $\kappa \mathrm{B}$ protein P65 (Fig. 4d). We further determined that pretreating cells with the NF- $\mathrm{KB}$ 

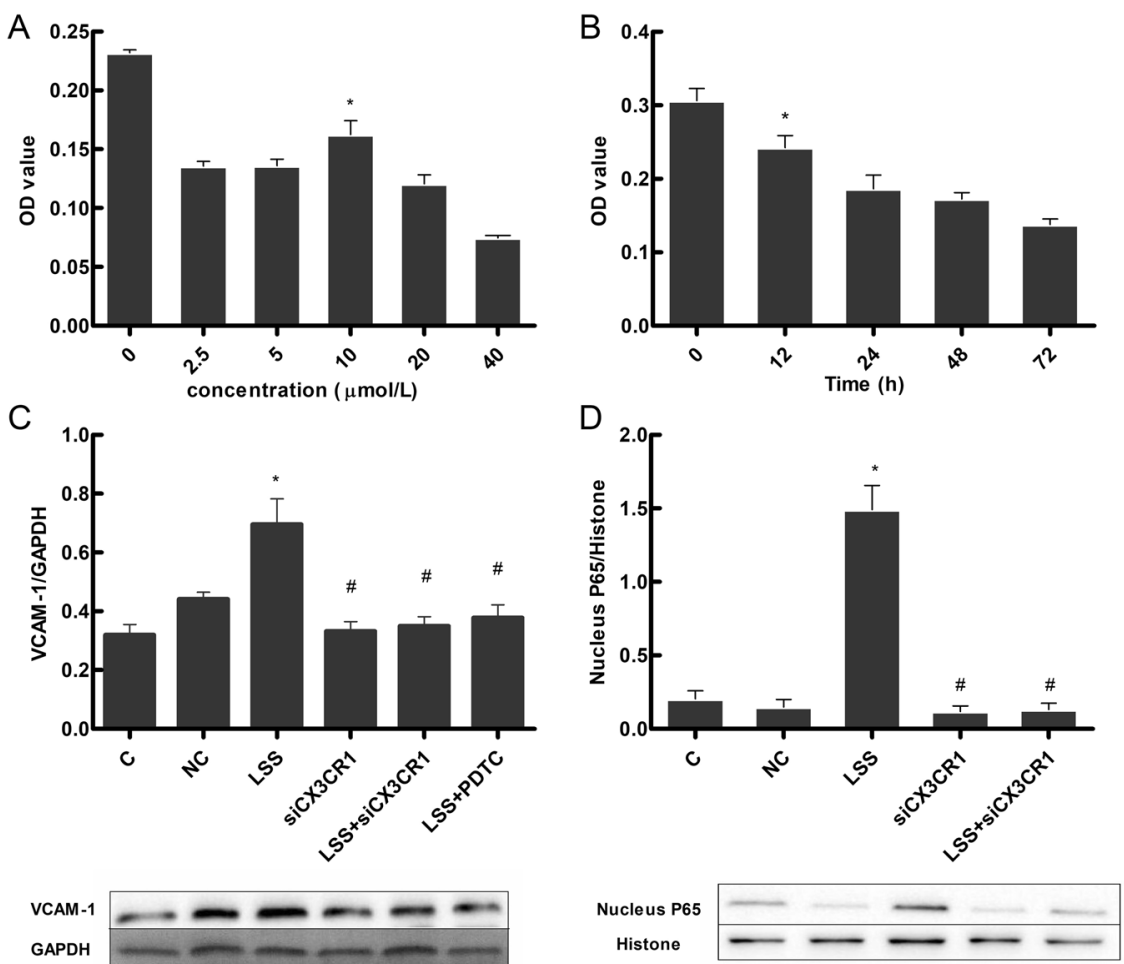

Fig. 4 NF- $\kappa B$ mediates CX3CR1-induced VCAM-1 expression under low shear stress. a CX3CR1 gene silencing and treatment with the NF$\kappa \mathrm{B}$ inhibitor PDTC reduced the increase in VCAM-1 expression caused by low shear stress. HUVECs were either transfected with specific siRNA against CX3CR1 for $72 \mathrm{~h}$ or incubated with PDTC $(10 \mu \mathrm{mol} / \mathrm{L})$ for $12 \mathrm{~h}$; VCAM-1 expression was determined using western blot analysis. b PDTC decreased cell viability in HUVECs. Cell viability was assessed using the MTT method. HUVECs were

inhibitor PDTC inhibited CX3CR1-induced VCAM-1 protein expression (Fig. 4c, d). Our data suggest that low shear stress upregulates CX3CR expression by inducing VCAM1 expression through the NF- $\mathrm{kB}$ pathway in VECs.

\section{Discussion}

Mechanical stress is a key factor underlying the pathophysiology of atherosclerosis. When VECs are continuously exposed to blood flow, they are subjected to different degrees of shear stress (resulting from tangential frictional force), including laminar shear stress and disturbed flow, which can affect endothelial cell function [22, 23]. This study provides evidence that low shear stress increased CX3CR1 expression in VECs, which resulted in an increase in VCAM-1 through NF- $\mathrm{KB}$ signaling.

Shear stress of $5-12$ dyne $/ \mathrm{cm}^{2}$ is essential to maintain the structural and functional integrity of VECs [24]. Blood flow lower than this range induces pro-inflammatory and prothrombotic genes and increases both VEC proliferation and

exposed to $10 \mu \mathrm{mol} / \mathrm{L}$ PDTC for $12 \mathrm{~h}$. c Inhibition of CX3CR 1 reduced the low shear stress-induced increase in P65 expression in HUVECs. d HUVECs were transfected with specific siRNA against CX3CR1 for $72 \mathrm{~h}$; nuclear P65 expression was determined using Western blot analysis. (C Control, NC Negative control, LSS low shear stress. ${ }^{*} P<0.05$ vs. control; ${ }^{\#} P<0.05$ vs. LSS alone. $n=3$ in each group)

apoptosis [25, 26]. Numerous studies have described the correlation between low shear stress and atherosclerosis. Low shear stress activates the MAPK pro-inflammatory signaling pathway and promotes endothelial cell apoptosis, which is mediated by increased ROS in the mitochondria and cytoplasm and can further activate the serine/threonine kinase Akt in VECs [27]. Cheng et al. found that low shear stress increased IL-8 levels by JNK1/2, ERK1/2, and p38 MAPK $[28,29]$. Our results indicate that low shear stress (4.14 dyne/ $\mathrm{cm}^{2}$ ) can also increase CX3CR1 expression that is dependent on NF- $\kappa B$ activation in EA.hy926 cells. CX3CR1 belongs to a family of $\mathrm{G}$ protein-coupled receptors, at the same time, we also subjected CX3CR1 protein were expression remained in the cell membrane after exposure to shear stress.

Our current findings support our previously published study demonstrating that CX3CL1 expression increases under low shear stress $\left(4.14 \mathrm{dyne} / \mathrm{cm}^{2}\right)$ [30]. However, we also found no significant difference about CX3CR1 expression varied with increasing levels of shear stress. Some study found that CX3CL1 expression were downregulated by high laminar shear stress in endothelial, and this were mediated by 
TNF $\alpha$ [31]. We previously demonstrated that CX3CR1 levels influence atherosclerotic plaque development in rabbits. Furthermore, we reported that shear stress affected FKN expression in VECs, as well as increased ERK1/2, p38, and JNK activation in a time-dependent manner [32]. Inhibiting this activation resulted in downregulation of FKN expression induced by low shear stress. These data demonstrate that low shear stress-induced CX3CR1 expression is closely related to the pathogenesis of atherosclerosis.

Subsequently, we investigated the mechanism by which low shear stress-induced CX3CR1 expression. We found that VCAM-1 increased in response to low shear stress after CX3CR1 silencing. Some findings indicated that atherosclerosis promoted low shear stress by activating the soluble form of VCAM-1 [12]. A previous study found that shear stress plays differential roles in modulating TNF- $\alpha$-induced VEC expression of VCAM-1 [33]. Therefore, we determined if VCAM-1 expression was downstream of low shear stressmediated CX3CR1 upregulation. CX3CR1 is a key factor in the vascular inflammatory response induced by low shear stress, and NF-kB is activated upon extracellular stimulation by certain cytokines, inflammatory factors, growth factors, and even specific physical factors [34]. Moreover, we found that low shear stress significantly increased NF-KB P65 expression in the nucleus. siRNA mediated CX3CR1 knockdown decreased NF- $\mathrm{kB}$ P65 expression similar to what we observed for VCAM-1 after treatment with the NF- $\mathrm{KB}$ antagonist PDTC and low shear stress. Taken together, our study indicates that NF-KB is activated by the CX3CR1 ligand in response to low shear stress.

In conclusion, Our study demonstrates that low shear stress increases CX3CR1 expression and that CX3CR1induced VCAM-1 expression is mediated by the NF- $\mathrm{KB}$ signaling pathway in response to low shear stress. The current data provide evidence of the correlation between shear stress and atherosclerosis that is regulated by CX3CR1.

Suggested reviewers: Zuzanna Rowinska: z.rowinska@klinikum-bochum.de. Rachana Shah: shahr@email. chop.edu. Andreas Ludwig: aludwig@ukaachen.de.

Acknowledgements This work was supported by the National Natural Science Foundation of China [grant no. 31860261] and the National Natural Science Foundation of China [grant no. 11462022].

\section{Compliance with Ethical Standards}

Conflict of Interest The authors declare that they have no conflict of interest.

Publisher's note Springer Nature remains neutral with regard to jurisdictional claims in published maps and institutional affiliations.

Open Access This article is licensed under a Creative Commons Attribution 4.0 International License, which permits use, sharing, adaptation, distribution and reproduction in any medium or format, as long as you give appropriate credit to the original author(s) and the source, provide a link to the Creative Commons license, and indicate if changes were made. The images or other third party material in this article are included in the article's Creative Commons license, unless indicated otherwise in a credit line to the material. If material is not included in the article's Creative Commons license and your intended use is not permitted by statutory regulation or exceeds the permitted use, you will need to obtain permission directly from the copyright holder. To view a copy of this license, visit http://creativecommons. org/licenses/by/4.0/.

\section{References}

1. Cai, H., \& Harrison, D. G. (2000). Endothelial dysfunction in cardiovascular diseases: the role of oxidant stress. Circulation Research, 87, 840-844.

2. Traub, O., \& Berk, B. C. (1998). Laminar shear stress: mechanisms by which endothelial cells transduce an atheroprotective force. Arteriosclerosis, Thrombosis, and Vascular Biology, 18, $677-685$.

3. Lehoux, S., \& Jones, E. A. (2016). Shear stress, arterial identity and atherosclerosis. Thrombosis and Haemostasis, 115, 467-473.

4. Zhou, J., Li, Y. S., \& Chien, S. (2014). Shear stress-initiated signaling and its regulation of endothelial function. Arteriosclerosis, Thrombosis, and Vascular Biology, 34, 2191-2198.

5. Libby, P.(2012). History of discovery (2012) inflammation in atherosclerosis. Arteriosclerosis, Thrombosis, and Vascular Biology, 9, 2045-2051.

6. Kwak, B. R., Back, M., Bochaton-Piallat, M. L., Caligiuri, G., Daemen, M. J., Davies, P. F., Hoefer, I. E., Holvoet, P., Jo, H., \& Krams, R. (2014). Biomechanical factors in atherosclerosis: mechanisms and clinical implications. European Heart Journal., 35, 3013-3020. 3020a-3020d.

7. Nigro, P., Abe, J., \& Berk, B. C. (2011). Flow shear stress and atherosclerosis: a matter of site specificity. Antioxidants \& Redox Signaling, 15, 1405-1414.

8. Wragg, J. W., Durant, S., Mcgttrick, H. M., Sample, K. M., Egginton, S., \& Bicknell, R. (2014). Shear stress regulated gene expression and angiogenesis in vascular endothelium. Microcirculation, 21, 290-300.

9. Chiu, J. J., \& Chien, S. (2011). Effects of disturbed flow on vascular endothelium: pathophysiological basis and clinical perspectives. Physiology Reviews, 91, 327-387.

10. Bazan, J. F., Bacon, K. B., Hardiman, G., Wang, W., Soo, K., Rossi, D., Greaves, D. R., Zlotnik, A., \& Schall, T. J. (1997). A new class of membrane-bound chemokine with a CX3C motif. Nature, 385, 640-644.

11. Imai, T., Hieshima, K., Haskell, C., Baba, M., Nagira, M., Nishimura, M., Kakizaki, M., Takagi, S., Nomiyama, H., \& Schall, T. J. (1997). Identification and molecular characterization of fractalkine receptor $\mathrm{CX} 3 \mathrm{CR} 1$, which mediates both leukocyte migration and adhesion. Cell, 91, 521-530.

12. Landsman, L., Bar-On, L., Zernecke, A., Kim, K. W., Krauthgamer, R., Shagdarsuren, E., Lira, S. A., Weissman, I. L., Weber, C., \& Jung, S. (2009). CX3CR1 is required for monocyte homeostasis and atherogenesis by promoting cell survival. Blood., 113, 963-972.

13. Lucas, A. D., Bursill, C., Guzik, T. J., Sadowski, J., Channon, K. M., \& Greaves, D. R. (2003). Smooth muscle cells in human atherosclerotic plaques express the fractalkine receptor CX3CR1 and undergo chemotaxis to the $\mathrm{CX} 3 \mathrm{C}$ chemokine fractalkine (CX3CL1). Circulation, 108, 2498-2504.

14. Poupel, L., Boissonnas, A., Hermand, P., Dorgham, K., Guyon, E., Auvynet, C., Charles, F., Lesnik, P., Deterre, P., \& Combadiere, C. (2013). Pharmacological inhibition of the chemokine 
receptor, CX3CR1, reduces atherosclerosis in mice. Arteriosclerosis, Thrombosis, and Vascular Biology, 33, 2297-2305.

15. Zhou, J. J., Wang, Y. M., Lee, V. W. S., Zhang, G. Y., Medbury, H., Williams, H., Wang, Y., Tan, T. K., Harris, D. C. H., \& Alexander, S. I. (2018). DEC205-DC targeted DNA vaccine against CX3CR1 protects against atherogenesis in mice. PLoS ONE, 13, e0195657.

16. Apostolakis, S., \& Spandidos, D. (2013). Chemokines and atherosclerosis: focus on the CX3CL1/CX3CR1 pathway. Acta Pharmacologia Sinica, 34, 1251-1256.

17. Liu, H., Jiang, D. (2011). Fractalkine/CX3CR1 and atherosclerosis. Clinica Chimica Acta, 412, 1180-1186.

18. Huang, X., Zeng, Y., Jiang, Y., Qin, Y., Luo, W., Xiang, S., Sooranna, S. R., \& Pinhu, L. (2017). Lipopolysaccharide-binding protein downregulates fractalkine through activation of p38 MAPK and NF-kappaB. Mediators of Inflammation, 2017, 1-20.

19. Kong, D. H., Kim, Y. K., Kim, M. R., Jang, J. H., \& Lee, S. (2018). Emerging roles of vascular cell adhesion molecule-1 (VCAM-1) in immunological disorders and cancer. International Journal of Molecular Sciences, 19, 1057-1073.

20. Alapati, A., Deosarkar, S. P., Lanier, O. L., Qi, C., Carlson, G. E., Burdick, M. M., Schwartz, F. L., McCall, K. D., Bergmeier, S. C., \& Goetz, D. J. (2015). Simple modifications to methimazole that enhance its inhibitory effect on tumor necrosis factor-alpha-induced vascular cell adhesion molecule-1 expression by human endothelial cells. European Journal of Pharmacology, 751, 59-66.

21. Pedrigi, R. M., Papadimitriou, K. I., Kondiboyina, A., Sidhu, S., Chau, J., Patel, M. B., Baeriswyl, D. C., Drakakis, E. M., \& Krams, R. (2017). Disturbed cyclical stretch of endothelial cells promotes nuclear expression of the pro-atherogenic transcription factor NF-kappaB. Annals of Biomedical Engineering, 45, 898-909.

22. Eshtehardi, P., McDaniel, M. C., Suo, J., Dhawan, S. S., Timmins, L. H., Binongo, J. N., Golub, K. J., Corban, M. T., Finn, A. V., \& Oshinski, J. N. (2012). Association of coronary wall shear stress with atherosclerotic plaque burden, composition, and distribution in patients with coronary artery disease. Journal of the American Heart Association, 1, e002543.

23. Vozzi, F., Bianchi, F., Ahluwalia, A., \& Domenici, C. (2014). Hydrostatic pressure and shear stress affect endothelin-1 and nitric oxide release by endothelial cells in bioreactors. Biotechnology Journal, 9, 146-154.
24. Resnick, N., Yahav, H., Shay-Salit, A., Shushy, M., Schubert, S., Zilberman, L. C., \& Wofovitz, E. (2003). Fluid shear stress and the vascular endothelium: for better and for worse. Progress in Biophysics and Molecular Biology, 81, 177-199.

25. Conway, D., \& Schwartz, M. (2013). Flow-dependent cellular mechanotransduction in atherosclerosis. Journal of Cell Science, 126, 5101-5109.

26. Hahn, C., \& Schwartz, M. (2009). Mechanotransduction in vascular physiology and atherogenesis. Nature Reviews Molecular Cell Biology, 10, 53-62.

27. Zhang, J., Wang, Z., Zuo, G., Li, B., Zhang, J., Tian, N., \& Chen, S. (2013). Low shear stress induces human vascular endothelial cell apoptosis by activating Akt signal and increasing reactive oxygen species. Journal of Southern Medical University, 33, 313-317.

28. Cheng, M., Wu, J., Li, Y., Nie, Y., \& Chen, H. (2018). Activation of MAPK participates in low shear stress-induced IL-8 gene expression in endothelial cells. Clinical Biomechanics, 23, S96-S103.

29. Cheng, M., Wu, J., Liu, X., Li, Y., Nie, Y., Li, L., \& Chen, H. (2009). Low shear stress-induced interleukin-8 mRNA expression in endothelial cells is mechanotransduced by integrins and the cytoskeleton. Endothelium, 14, 265-273.

30. Lesnik, P., Haskell, C. A., \& Charo, I. F. (2003). Decreased atherosclerosis in CX3CR1-/- mice reveals a role for fractalkine in atherogenesis. J CLIN INVEST, 111, 333-340.

31. Babendreyer, A., Molls, L., Dreymueller, D., Uhlig, S., \& Ludwig, A. (2017). Shear stress counteracts endothelial CX3CL1 induction and monocytic cell adhesion. Mediators Inflamm, 2017, $1-10$.

32. Ruze, A., Zhao, Y., Li, H., Gulireba, X., Li, J., Lei, D., Dai, H., Wu, J., Zhao, X., \& Nie, Y. (2018). Low shear stress upregulates the expression of fractalkine through the activation of mitogenactivated protein kinases in endothelial cells. Blood Coagul Fibrinolysis, 29, 361-368.

33. Chiu, J. J., Lee, P. L., Chen, C. N., Lee, C. I., Chang, S. F., Chen, L. J., Lien, S. C., Ko, Y. C., Usami, S., \& Chien, S. (2004). Shear stress increases ICAM-1 and decreases VCAM-1 and E-selectin expressions induced by tumor necrosis factor-[alpha] in endothelial cells. Arterioscler Thromb Vasc Biol, 24, 73-79.

34. Yu, X. H., Zheng, X. L., \& Tang, C. K. (2015). Nuclear factorkappaB activation as a pathological mechanism of lipid metabolism and atherosclerosis. Adv Clin Chem, 70, 1-30. 